\title{
Dominancia Colectiva: Análisis de la sentencia del pasado 25 de JUNIO de 2018, en QUe la Corte Suprema acogió la reclamación deducida por la Corporación Nacional de Consumidores y Usuarios de Chile, Asociación de Consumidores en contra de la Sentencia No 154/2016 del Tribunal de Defensa de la Libre Competencia
}

\section{Analysis of the JUdGment dated JUne 25, 2018, in Which the SUPReme Court accepted the Claim submitted by the National Consumers and Users Corporation of the Chile, Consumers Association against Decision No. 154/2016 of Chilean Competition Court}

Gabriel Budnik Ojeda* Trabajo recibido el 30 de noviembre de 2018 y aprobado el 3 de junio de 2019

\section{ResUMEN}

El presente comentario analizará la sentencia del pasado 25 de junio de 2018, en que la Corte Suprema acogió la reclamación deducida por la Corporación Nacional de Consumidores y Usuarios de Chile, Asociación de Consumidores (indistintamente "Conadecus" o la "Demandante") en contra de la Sentencia No 154/2016 del Tribunal de Defensa de la Libre Competencia ("TDLC"), pronunciada con fecha 15 de septiembre de 2016, en la que se rechazó, con expresa condena en costas, la demanda de Conadecus en contra de Telefónica Móviles Chile S.A. ("Telefónica"), Claro Chile S.A. ("Claro") y Entel PCS Telecomunicaciones S.A. ("Entel" y conjuntamente con Telefónica y Claro, las "Demandadas").

Más allá del análisis específico del ilícito infraccional del artículo 30 letra b) del Decreto Ley № 211 , en los siguientes párrafos se analizará uno de los presupuestos para la configuración de un abuso de posición dominante, a saber, la existencia de una posición de dominio y, en lo que importa al fallo, la dominancia colectiva.

Palabras clave: Derecho de la Libre Competencia; artículo 30 letra b) del Decreto Ley № 211; abuso de posición dominante; y dominancia colectiva.

\section{Abstract}

This jurisprudential comment will analyze the judgment dated June 25, 2018, in which the Supreme Court accepted the claim deduced by the National Consumer and Users Corporation of Chile, Consu-

* Gabriel Budnik Ojeda. Abogado, Universidad de Chile. Es Asociado Libre Competencia en Philippi Prietocarrizosa Ferrero DU \& Uría. Correo de contacto: budnikojeda@gmail.com 
mers Association ("Conadecus") against the Decision No. 154/2016 of the Chilean Competition Court, dated September 15, 2016, in which Conadecus's lawsuit against different telecommunication companies.

Beyond the specific analysis of article 3 letter b) of Law Decree No. 211, the following paragraphs will analyze one of the assumptions for the configuration of an abuse of a dominant position, namely, the existence of a dominant position and, where it matters to the Supreme Court's decision, collective dominance.

Keywords: Competition Law; article 3, letter b) of Law Decree No. 211; abuse of a dominant position; and collective dominance.

\section{HeCHOS}

Con fecha 6 de marzo de 2014, Conadecus interpuso una demanda en contra de las Demandadas porque, en su concepto, habrían infringido el artículo $3^{\circ}$ del Decreto Ley № 211, al participar en el "Concurso público para otorgar concesiones de Servicio Público de Transmisión de Datos en las bandas de frecuencia de 713-748 MHz y 768-803 MHz" ("Concurso 700 MHz") convocado por la Subsecretaría de Telecomunicaciones, excediendo los límites de espectro radioeléctrico del cual cada operador podría disponer lícitamente $(60 \mathrm{MHz}$ ), acaparando espectro y poniendo en peligro su uso efectivo y eficiente.

Al respecto, la Demandante argumentó que, dado que las Demandadas son empresas "superdominantes", sobre ellas pesaría un especial deber de cuidado, debiendo velar porque sus conductas no atenten en contra de la libre competencia.

Con fecha 15 de septiembre de 2016, el TDLC dictó su sentencia, rechazando la demanda en su totalidad, con expresa condena en costas, al determinar que no existía evidencia clara y concluyente de que las Demandantes hayan participado en el Concurso $700 \mathrm{MHz}$ con el fin estratégico de acaparar espectro y poner en peligro su uso efectivo y eficiente. En el mismo sentido, el TDLC Ilegó a la conclusión que no existe evidencia destinada a probar los efectos exclusorios o de cierre de mercado derivados de dicha conducta.

Producto del fallo negativo, Conadecus, con fecha 28 de septiembre de 2016, interpuso en recurso de reclamación en contra de la sentencia del TDLC, solicitando enmendar la referida sentencia y, en su reemplazo, dar lugar a la demanda en todas sus partes, declarando la infracción por parte de las Demandadas al artículo $3^{\circ}$ del Decreto Ley № 211, al acaparar e intentar acaparar espectro radioeléctrico, con el objeto de impedir, restringir y entorpecer la competencia en el mercado de la telefonía móvil, bloqueando o retardando en los hechos el ingreso de nuevos competidores a dicho mercado.

Finalmente, con fecha 25 de junio de 2018, la Corte Suprema decidió acoger el recurso de reclamación en contra de la Sentencia No 154/2016, estableciendo que las Demandadas han incurrido en una conducta anticompetitiva al adjudicarse bloques en la licitación del Concurso $700 \mathrm{MHz}$, sin respetar el límite de $60 \mathrm{MHz}$ impuesto como máximo que puede tener cada incumbente en el mercado de servicios avanzados de comunicaciones móviles, infringiendo el artículo $3^{\circ}$ del Decreto Ley № 211.

Con ocasión de lo anterior, la Corte Suprema ordenó a las Demandadas desprenderse de la misma cantidad de espectro radioeléctrico que fue adquirido en el Concurso $700 \mathrm{MHz}$, quedando a su opción la

1 Conforme a lo establecido por la Corte Suprema mediante sentencia de fecha 27 de enero de 2009 dictada en la causa rol 4797-08, así como por el TDLC en su Resolución № 2/2005.

BUDNIK OJEDA, Gabriel. Dominancia Colectiva: Análisis de la sentencia del pasado 25 de junio de 2018, en que la Corte Suprema acogió la reclamación deducida por la Corporación Nacional de Consumidores y Usuarios de Chile, Asociación de Consumidores en contra de la Sentencia № 154/2016 del Tribunal de Defensa de la Libre Competencia. Revista Justicia y Derecho, Santiago, v. 2, no 1, 2019 
elección de la banda que será enajenada.

\section{Mercado ReleVAnte afectado y participaciones de MERCAdo}

En cuanto al mercado relevante, ambas instancias están contestes de que se trataría del de los servicios analógicos y digitales de telefonía y datos móviles en Chile, dentro del cual se puede distinguir entre los Operadores Móviles de Red ("OMR"), quienes son propietarios de determinadas redes y entre los Operadores Móviles Virtuales ("OMV"), quienes adquieren acceso a redes - de propiedad de los OMR-y prestan el servicio de telecomunicación móvil a los consumidores finales.

De esta forma, la industria de servicios móviles está conformada por un mercado mayorista o aguas arriba, en el que se transa el acceso a las redes móviles y por un mercado aguas abajo, consistente en la comercialización a nivel minorista de servicios analógicos y digitales de telecomunicaciones móviles.

Las Demandadas participan en ambos mercados descritos y, por ende, los actos de acaparamiento demandados podrían afectar la entrada o crecimiento de competidores en los mercados mayoristas (directamente, cerrando el mercado a nuevos competidores) y minorista (indirectamente, al inhibir eventualmente la entrada de nuevas empresas como OMR o como OMV) de servicios de telecomunicaciones móviles.

En cuanto a las participaciones de mercado, es importante destacar que ninguna de las Demandadas, individualmente consideradas, supera un 30\% de participación de mercado.

\section{ILÍCITO INFRACCIONAL}

Si bien Conadecus demanda a las Demandadas con base en el artículo 30, inciso primero del Decreto Ley No 211, la conducta demandada obedece, en la especie, a la letra b) del mismo artículo, esto es, a un abuso de una posición dominante. Así lo reconoce el TDLC en su sentencia (Considerando Vigésimo cuarto) y el voto de minoría de la sentencia de la Corte Suprema (numeral 6).

Por su parte, éste parece ser el mismo raciocinio que tiene la sentencia de la Corte Suprema, toda vez que analiza la relación vertical que se generaría entre la Demandadas tanto como proveedoras (aguas arriba) como comercializadoras a nivel minorista de servicios analógicos y digitales de telecomunicaciones móviles (aguas abajo), para luego recordar lo dicho por la doctrina en relación al principio de neutralidad ${ }^{2}$. A propósito de lo mismo, en los siguientes considerandos, la sentencia en comento pasa a analizar la existencia o no de una posición dominante por parte de las Demandadas, (i.e., uno de los dos requisitos del tipo infraccional de la letra b) del artículo $3^{\circ}$ del Decreto Ley № $211^{3}$ ).

2 "Para paliar los potenciales efectos adversos de la integración vertical, el marco regulatorio establece el principio de neutralidad. Por este principio, la empresa que controla los mercados verticalmente, no debe usar el poder que tiene en un mercado para actuar en el otro de manera anticompetitiva (por ejemplo, cláusulas de atadura) ni imputar los gastos de un mercado poco rentable a otro más rentable (subsidios cruzados) sino que debe actuar en cada mercado como si no tuviera actuación en el otro u otros". Considerando Duodécimo sentencia Corte Suprema. Citando a Tovar Mena, Teresa V., "Las telecomunicaciones y la libre competencia: un marco analítico básico", Revista lus et veritas, N²8, año 2004, p. 140).

3 Acreditada la existencia de una posición dominante, correspondería analizar el segundo requisito del tipo, esto es, el abuso de dicha posición. Se ha dicho que un agente económico abusa de su posición dominante cuando hace un "mal uso del poder de mercado" (Valdés (2016), p. 561). Este abuso se ha de entender como un concepto objetivo, relativo al comportamiento y los

BUDNIK OJEDA, Gabriel. Dominancia Colectiva: Análisis de la sentencia del pasado 25 de junio de 2018, en que la Corte Suprema acogió la reclamación deducida por la Corporación Nacional de Consumidores y Usuarios de Chile, Asociación de Consumidores en contra de la Sentencia № 154/2016 del Tribunal de Defensa de la Libre Competencia. Revista Justicia y Derecho, Santiago, v. 2, no 1, 2019 
En cuanto al concepto de posición dominante, resulta útil recordar que el TDLC la ha definido como "[l]a habilidad para actuar con independencia de otros competidores y del mercado, fijando o estableciendo condiciones que no habrían podido obtenerse de no mediar dicho poder"4. De forma similar, el Tribunal de Justicia de la Unión Europea ha entendido por posición dominante la "posición de poder económico de una empresa que le permite obstaculizar el mantenimiento de una competencia efectiva en el mercado de referencia, al darle la posibilidad de actuar en buena medida independientemente de sus competidores, de sus clientes y en definitiva de los consumidores" ${ }^{\prime \prime}$.

En Chile, si bien no existe una norma expresa que establezca un umbral para acreditar la existencia de una posición dominante, se entiende que existe una posición dominante si es que un agente tiene una participación de un 35\% o superior en un mercado relevante específico.

En tal sentido, respecto de restricciones verticales, la FNE ha indicado que apreciará en términos generales como lícita una restricción vertical cuando la cuota de mercado del vendedor, en el mercado donde vende los productos objeto del contrato, y la cuota de mercado del comprador, en el mercado donde adquiere los productos objeto del contrato, sean cada una del 35\% o menos.

Por su parte, el TDLC no ha fijado un estándar inequívoco en torno a cuál es el porcentaje de participación de mercado para presumir que existe una posición de dominio y, de hecho, existen casos anteriores en que una participación de mercado inferior al 35\% ha sido entendida como dominante 6 .

Sin perjuicio de las participaciones de mercado, es importante tener en consideración que el artículo $3^{\circ}$, letra b) en comento, acepta dos formas en que se puede concretar un abuso de posición dominante, al establecer que la explotación abusiva de una posición dominante en un mercado puede efectuarse (i) por parte de un agente económico o (ii) por un conjunto de ellos.

Lo anterior no es baladí, toda vez que uno de los argumentos que justifica la decisión de la Corte Suprema, contrariando lo dicho por el TDLC, es la supuesta existencia de un abuso de posición dominante colectivo.

En relación a la posición de dominio ostentada por un grupo de personas, se ha indicado ${ }^{78}$ que, cuando ésta no es resultado de un ilícito monopólico de fuente, como es la colusión?, sino que producto de un actuar organizado -pero no concertado-, propio de un paralelismo consciente (interdependencia oligopolística y conciencia de dicha interdependencia), es posible hablar de dominancia colectiva.

Acudiendo a la jurisprudencia comparada, en particular a la decisión en Airtours ${ }^{10}$, parece prudente considerar los siguientes requisitos para la existencia de dominancia colectiva:

medios utilizados por la empresa dominante (Tribunal de Justicia de la Unión Europea, Sentencia asunto Nº 85/76).

4 TDLC, Sentencia No 112/2011.

5 Tribunal de Justicia de la Unión Europea, Sentencia asunto N²7/76.

6 Así, por ejemplo: TDLC, Sentencia No 24/2005 (33\%) y 39/2006 (32\%).

7 Valdés (2016), p. 561.

8 Se entiende por dominancia colectiva la "relación de interdependencia que existe entre los miembros de un oligopolio estrecho dentro del cual, en un mercado con las características apropiadas, en especial en términos de concentración del mercado, de transparencia y de homogeneidad del producto, puede prever sus comportamientos recíprocos y se ven, por lo tanto, en gran medida impulsados a coordinar sus beneficios comunes, restringiendo la producción con el fin de aumentar los precios. En efecto, en tal contexto, cada operador sabe que una actuación altamente competitiva por su parte, dirigida a incrementar su cuota de mercado (por ejemplo, una reducción de precios), provocaría una actuación idéntica por parte de los demás, de manera que no obtendría ningún beneficio de su iniciativa. Todos los operadores tendrían por lo tanto que soportar el descenso del nivel de los precios" (STPI de 25 de marzo de 1999, Gencor Ltd. C. Comisión Europea, Asunto T-102/96 (Rec. 1999, p. Il.753), FJ 276).

9 Conducta que, en el caso de autos, no forma parte de la Demanda y que, de todos modos, no existió.

10 Decisión de la Comisión Europea 2000/276/CE, de fecha 22 de septiembre de 1999. Asunto Nº IV/M.-1524-Airtours/First Choice.

BUDNIK OJEDA, Gabriel. Dominancia Colectiva: Análisis de la sentencia del pasado 25 de junio de 2018, en que la Corte Suprema acogió la reclamación deducida por la Corporación Nacional de Consumidores y Usuarios de Chile, Asociación de Consumidores en contra de la Sentencia № 154/2016 del Tribunal de Defensa de la Libre Competencia. Revista Justicia y Derecho, Santiago, v. 2, no 1, 2019 
1. Transparencia: todos los miembros del oligopolio dominante deben poder conocer el comportamiento de los demás miembros, de modo de poder ejercer un control suficiente sobre el cumplimiento de las condiciones de la coordinación.

2. Sostenibilidad: coordinación tácita debe poder mantenerse en el tiempo, debiendo existir un mecanismo de represalia creíble para las empresas incumplidoras.

3. Ausencia de presión competitiva: acreditar que la reacción previsible por parte de los competidores actuales y potenciales y de los consumidores no cuestionaría los resultados esperados de la línea de acción coordinada.

Ahora bien, la Corte Suprema no parece haber seguido los criterios jurisprudencial y doctrinariamente aceptados.

\section{Críticas a la sentencia de la Corte Suprema}

Si bien es efectivo que, tal como señala la Corte Suprema en su considerando Décimo tercero, son varios los factores, estructurales y de conducta, que determinan que una empresa se encuentre en una posición de dominio, como, por ejemplo, las participaciones de mercado, la concentración de la industria (características oligopolísticas) y la existencia de barreras a la entrada, concluir que la mera existencia de un mercado oligopólico, en conjunto con la existencia de altas barreras a la entrada conlleva, necesariamente, a un abuso de posición dominante colectiva, parece, por decir lo menos, erróneo.

De esta forma, a juicio del autor de este comentario de jurisprudencia, la Corte Suprema termina desautorizando la decisión categórica del TDLC (sentencia que, como se comentó, el TDLC sancionó con expresa condena en costas a Conadecus), sin sustento (o al menos análisis) legal ni económico alguno. No parece correcto que, en un caso de abuso de posición dominante, propio del artículo 30, letra b) del Decreto Ley № 211, la Demandante, habiendo sólo demandado la infracción al ilícito general del artículo 30, inciso primero (tipo universal), y sin haber acreditado los requisitos del tipo por el cual la Corte Suprema termina accediendo a la demanda, obtenga un fallo favorable.

Lo anterior, no sólo vulnera el principio procesal de la carga de la pruebaํ', en virtud del cual corresponde a la Demandante probar la existencia de una acción que produce daño a la libre competencia, sino que, en última instancia, amenaza la estabilidad de un sistema que, hasta la fecha, ha probado ser eficaz.

\section{Conclusiones}

La sentencia en comento hace el esfuerzo de desarrollar uno de los temas ampliamente discutidos, pero poco entendidos, en materia de abuso de posición dominante, a saber: la dominancia colectiva. Ahora bien, dicho esfuerzo parece vacío, toda vez que, en vez de ahondar en los requisitos de procedencia de la misma, la Corte Suprema realiza un salto cuántico, determinando que, dados ciertos factores estructurales y conductuales, las Demandadas, colectivamente, ostentan de una posición dominante.

11 Por analogía a lo dispuesto en los artículos 1547 y 1698 del Código Civil. 